\title{
Impact of pine invasion on the taxonomic and phylogenetic diversity of a relict Mediterranean forest ecosystem
}

\author{
Federico Selvi ${ }^{a, *}$, Elisa Carrari ${ }^{a}$, Andrea Coppi ${ }^{b}$

 \\ ${ }^{\mathrm{b}}$ University of Firenze, Department of Biology, Botanical Laboratories, Via G. La Pira 4, 50121 Firenze, Italy
}

\section{A R T I C L E I N F O}

\section{Article history:}

Received 24 September 2015

Received in revised form 11 February 2016

Accepted 11 February 2016

\section{Keywords:}

Invasive species

Mediterranean forests

Pine tree

Phylogenetic diversity

Soil acidification

Species richness

\begin{abstract}
A B S T R A C T
Invasion by non-native tree species is a major driver of reduction and fragmentation of forest ecosystems, also altering biodiversity components. However, the effects of this process on the phylogenetic structure and diversity of Mediterranean woodlands are still unknown. Accordingly, we used cork oak (Quercus suber) stands invaded by self-sowing populations of maritime pine locally introduced ca. 70 years ago as a model system to assess the impact on the taxonomic and phylogenetic diversity of the native seed plant community. We performed vegetation sampling of the two forest types in sites of central Italy with similar conditions. Taxonomic diversity was negatively affected by the pine at three levels (gamma, alpha, beta). Indicator species were significantly less numerous than in cork oak stands, and did not include two growth-forms such as herbs and vines. Phylogenetic diversity metrics were inferred from an evolutionary tree of seed plants based on a ITS-5.8S nuclear DNA dataset including original sequences from local plant material. Phylogenetic diversity (PD) was positively related to species and genus richness, showing a marked decrease in the pine stands. Seven major clades (orders) of angiosperm dicots were only represented in the cork oak community. Both the NRI and NTI indices showed a significant reduction of phylogenetic evenness in the pine forest. Here, the proportional increase of related taxa with acid-tolerance specialization suggests that soil acidification is a major driver for a "habitat filtering" effect causing the exclusion of several understorey species and genera of cork oak forests. Progressive thinning of the pine stands is advocated to avoid further acidification and promote the re-conversion to oak woodlands by natural regeneration. This will ultimately favor the recovery of the associated plant diversity and the restoration of a vanishing forest ecosystem of the ancient Mediterranean landscape.
\end{abstract}

(C) 2016 Elsevier B.V. All rights reserved.

\section{Introduction}

Introductions of alien tree species, both deliberate and inadvertent, have caused the reduction and fragmentation of native forests around the world (Jose et al., 2008). The structure and functioning of the invaded ecosystems have been largely influenced via changes in their species composition, especially driven by nonnative trees that tend to form monospecific stands. Since functions are often supported by a suite of species that are characteristic of a particular habitat (Jose et al., 2008), understanding the changes in composition, richness, diversity and abundance of the native plants is the first step to predict the overall impact of the invasion process. Species richness and composition, however, do not account for the possible consequences on another key component of diversity, that related to the phylogenetic relationships within floristic

\footnotetext{
* Corresponding author.

E-mail address: federico.selvi@unifi.it (F. Selvi).
}

assemblages, or phylogenetic diversity. According to Faith (1992), this can be defined as the total amount of evolutionary distance among plant species in a community, which is determined by how related species are to each other. Such a "deep" component of diversity has been suggested to be relevant for ecosystem functioning (Srivastava et al., 2012) and services (Faith et al., 2010) as well as processes such as extinction (Purvis et al., 2000) and biotic invasion (Winter et al., 2009; Lapiedra et al., 2015; Constán-Nava et al., 2015). According to Winter et al. (2009), the latter has the potential to cause dramatic changes of also the phylogenetic diversity of native plant assemblages. On the other hand, maintaining genetic diversity and the evolutionary potential of all species within and across communities is considered one of the most important goals in biological conservation actions and sustainable environmental management, since this may enable rapid adaptation to changing habitat conditions across ecologic and evolutionary time scales (Jump et al., 2009; Rodrigues and Gaston, 2002). Indeed, the analysis of evolutionary relationships 
among overstorey trees has been shown to be relevant for the assessment of health conditions, sustainability and productivity of the forested ecosystems in north America, with implications for their broad-scale monitoring in the face of global changes and stress factors (Potter and Koch, 2014; Potter and Woodall, 2014). Hence, gaining new insights into the organization of forest communities from an evolutionary perspective and assessing the impact of disturbance processes such as biotic invasion may have important implications for the conservation of their integrity in the long-term.

Looking at the Old-World temperate forests, however, these aspects are still largely unknown and no evidence exists about the effects of invasive trees on the phylogenetic structure and diversity of Mediterranean woodlands. These ecosystems represent a major hot-spots of diversity and endemism at the global scale and provide multiple goods and services that are crucial for the socio-economic development of rural areas and for the welfare of the urban populations (Scarascia et al., 2000; Quézel and Médail, 2003). However, several threats exist that make these forests vulnerable especially in the face of climate and land-use changes (Palahi et al., 2008). An emblematic example of declining ecosystem are the woodlands dominated by the cork oak (Quercus suber), one of the most characteristic components of the ancient Mediterranean landscape as a result of either the longevity and size of the species or its usefulness to humans (Pereira et al., 2009). These woodlands harbor a remarkable richness of both animal and plant taxa, several of which are threatened at a global or regional scale (Berrahmouni et al., 2009; Selvi and Valleri, 2012). In recent times, cork oak forests have decreased in surface and vitality with negative consequences on the conservation status of these species, as well as on ecosystem functionality and resilience. Expansion of agriculture, overgrazing, fires, pests, global climate change and afforestation with non-native trees are the major drivers of this decline (Aronson et al., 2009).

One of the problems is the spread of non-native populations of conifer trees such as the maritime pine (Pinus pinaster; Selvi, 2009), a species widely used for afforestation purposes across the Mediterranean countries (Andrés and Ojeda, 2002) and in the southern Hemisphere (Richardson et al., 1994). Native to the humid parts of the western Mediterranean regions under the Atlantic climatic influence, it reaches the eastern limit of its range in Liguria and NW Tuscany in Italy (Agostini, 1968). From these small Italian native areas, it was extensively introduced around 60-70 years ago in several parts of central Italy with a less humid climate to quickly re-establish a forest cover in shrublands and garrigues resulting from the degradation of the native deciduous and/or evergreen woodlands (Gabellini and De Dominicis, 2003). As the two species have similar requirements, the maritime pine found favorable climate and soil conditions and outcompeted the cork oak in these areas with degraded forest vegetation, due to its faster growth and regeneration rate. In many sites, recurring wildfires have further favoured it thanks to its pioneer character and regeneration ability after burning events (Fernandes and Rigolot, 2007). At present, secondary pine stands form patches with an extensive total surface 26376 ha in Tuscany (Tabacchi et al., 2007), that was once mostly covered with native evergreen woodlands, thus causing their further fragmentation. This mosaic-like forest landscape provided an unintentional experimental setting to investigate the impact of pine invasion on the taxonomic and phylogenetic diversity of a typical Mediterranean forest type. To our knowledge, this topic was never studied before. Previous studies have described the effects of maritime pine plantations on species richness of open, tree-less Mediterranean ecosystems, such as serpentine vegetation (Chiarucci and De Dominicis, 1995) or montane heathlands (Andrés and Ojeda, 2002), but not on forest communities.
Measurement of phylogenetic diversity requires maximally resolved trees of the species in a community or its samples, which is often a major problem because DNA sequence data are still lacking for a significant proportion of plant taxa. Most case-studies published so far (e.g., Arroyo Rodríguez et al., 2012; Qian et al., 2014) relied on trees produced from on-line sources that are often incompletely resolved at the species level. As this was the case for also our study, we estimated relationships from a ad-hoc phylogenetic tree from a DNA dataset including both accessions from public databases and original gene sequencing work. New sequences were obtained for those taxa still not investigated for our genomic regions using plant material collected in the sampling sites and analyzed with molecular methods. By this approach we found a strong impact of pine cover on the phylogenetic structure and diversity of the native community, suggesting that non-native conifers with invasive behavior may represent a serious hazard for similar forest types in other regions, and possible management strategies that may help to restore and conserve a unique Mediterranean habitat.

\section{Materials and methods}

\subsection{Study site}

This investigation was carried out in the so called region of "Maremma" in south Tuscany (central Italy), where cork oak forests are at their eastern limit of natural distribution and under relative geographical isolation. This habitat is described as "very local, relict coastal forests of Tuscany and Latium" (Quercion suberis) in the Corine Manual (habitat no. 45.214 in Corine Biotopes Manual, 1991 ) and is recognized as of high conservation value under the EU Habitat Directive 92/43 (no. 9330). The study area (42 $53^{\prime}-4$ $3^{\circ} 09^{\prime} \mathrm{N}$ to $11^{\circ} 06^{\prime}-11^{\circ} 17^{\prime} \mathrm{E}$; ca. $320 \mathrm{~km}^{2}$; Fig. 1), is part of a vast complex of hills of the Antiapennine system with an altitudinal range of 75-450 $\mathrm{m}$ above sea level. With $720-820 \mathrm{~mm}$ of mean annual rainfall, ca. 3 months of drought and $14-14.5^{\circ} \mathrm{C}$ of mean annual temperature, the bioclimate of this area is typically mesomediterranean. The hill system covered by the forest types object of this study is geologically homogeneous and consists of siliceous crystalline rocks of quartzitic-anagenitic type. Soils deriving from this formation belong to the broad category of Cambisols (V.V. A. A., Soil Atlas of Europe), but are often shallow, nutrient-poor and subject to summer drought and acidification, also depending on the forest type.

The area is largely covered by forest vegetation (over $50 \%$ of the territory), mainly consisting of native evergreen sclerophyllous communities. Secondary conifer woodlands of maritime pine occur with large patches on especially hill slopes and ridges, therefore forming a mosaic with the native evergreen woodlands. From a syntaxonomical point of view, the local cork oak forests belong to the associations Cytiso villosi-Quercetum suberis and Simethido mattiazzi-Q. suberis (Selvi and Viciani, 1999), while the maritime pine-dominated community has been referred to the association Tuberario lignosae-Callunetum vulgaris (Gabellini and De Dominicis, 2003).

The study area includes Nature Reserves and sites of the ReteNatura 2000 network, such as "Monte Leoni" (code: IT51A0009) and "Val di Farma" (IT51A0003).

\subsection{Study design and data collection}

Field sampling was performed by means of 66 vegetation plots in representative cork oak (33) and maritime pine stands (33), measuring $15 \times 10 \mathrm{~m}$ in size. Cork oak stands were native while pine stands were mainly second-generation forests originated from 


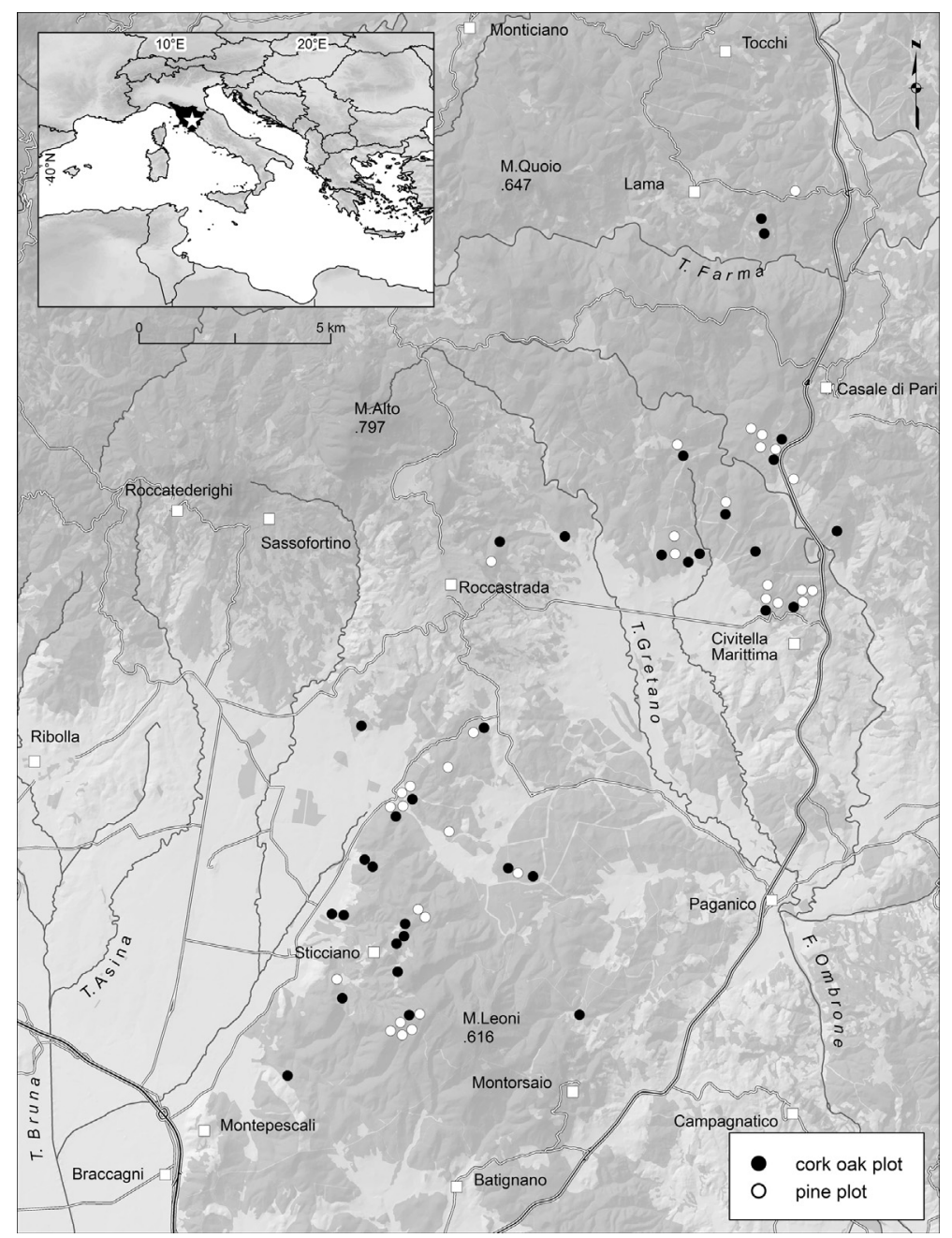

Fig. 1. Geographic location of the study area in Tuscany (central Italy), with approximate location of the sampling sites.

natural regeneration of the trees that were artificially seeded some decades ago. Based on local common knowledge and historical documents, forest cover has been continuous in the area of the plots, with no evidence for past conversions to agricultural uses. Especially after the 2nd world war the woodlands in the area were much degraded because of fires and over-exploitation (firewood, wood charcoal, other materials), so that a policy of forest recovery was pursued employing the local populations for the preparation of the ground (holes, furrows) and the pine sowing operations on the hills with siliceous parent rock.

Thanks to the mosaic-like vegetation landscape formed today by these two forest types, it was possible to sample representative stands in geographical proximity, and with a similar number of plots in the different parts of the study area. This allowed us to keep variation of the main climate, geo-lithological and soil conditions at minimum, while altitude, slope aspect and inclination were not controlled. Plots were scattered over the whole area, therefore allowing us to catch local variations in species composition of the respective communities and reducing spatial autocorrelation. For the geographical details of the studied sites see "Supplementary material". Vegetation structure and physiognomy was relatively uniform between the plots of the two forest types. Cork oak stands had a canopy cover of $Q$. suber $\geqslant 50 \%$ (mean $=86 \% \pm 5.1$ ) and not more than $10 \%$ cover of pine, and vice versa (mean $P$. pinaster cover in pine stands $=81 \% \pm 7.9$ ). Mixtures with a similar abundance of cork oak and pine were uncommon compared to areas alternately dominated by one or the other species. All plots were located in stands left to natural development and not disturbed by recent silvicultural management. The shrub layer was consequently well developed in both forest types.

The plot area $\left(150 \mathrm{~m}^{2}\right)$ was surveyed for total ground cover and floristic composition in each layer, scoring all vascular plants for cover percentage (Kent and Coker, 1992). Plant identification was mostly performed in the field based on Selvi (2010). Portions of leaf tissue of 13 species to be subsequently analyzed for DNA data (see below) were collected from plants within the plot area and rapidly dried in silica-gel. Voucher specimens are kept in the Herbarium of the Natural History Museum of the University of Florence, Italy (FI).

At the four corners and in the center of ten randomly selected plots per forest type, five soil cores of $15 \mathrm{~cm}$ were collected using steel cylinders. Samples were dried, sieved and mixed together to obtain one composite sample per plot that was analyzed for $\mathrm{pH}$ $\left(\mathrm{H}_{2} \mathrm{O}\right)$.

\subsection{Selection of molecular markers, DNA isolation, sequence alignment and tree construction}

Phylogenetic diversity of the spermatophyte communities in the plots (e.g., excluding ferns) was inferred from a super-tree 
obtained from the analysis of three markers from the Internal Transcribed Spacers of the nuclear ribosomal DNA, the ITS1-5.8S and ITS2 regions. The first reason for using these markers as an indicator of evolutionary relationships is that, despite some potential flaws, they are by far the most widely used to date for phylogenetic inference in spermatophytes. This allowed us to assemble the sequence dataset retrieving accessions of most species in our plots from available sources. Second, the (generally) greater discriminatory power of nrITS over plastid regions at low taxonomic levels (species) is well documented in seed plant systematics (e.g., Feliner and Rosselló, 2007; Hollingsworth et al., 2011), supporting this region as a core barcode for spermatophytes ( $\mathrm{Li}$ et al., 2011). Using these markers allowed us to avoid polytomic groups and to obtain a resolved tree even for those genera with two or more species (e.g., Brachypodium, Cytisus, and others).

Molecular sequence data for 63 out of the 76 species in our vegetation sample were taken from GenBank (http://www.ncbi.nlm. nih.gov/), using the accession numbers given in Appendix A. Hence, analysis was performed for 13 species that were not available from this database. Isolation of genomic DNA followed a modified $2 \times$ CTAB protocol (Doyle and Doyle, 1990) successfully adopted in our previous studies using molecular tools (see Coppi et al., 2008 and references therein). Amplification of the ITS region was performed using the primers ITS4 and ITS5 (White et al., 1990). Polymerase chain reactions were performed in a total volume of $25 \mu \mathrm{l}$ containing $2.5 \mu \mathrm{l}$ of $10 \times$ reaction buffer (Dynazyme II, Finnzyme, Espoo, Finland), $1.5 \mathrm{mM} \mathrm{MgCl} 2,10 \mathrm{pmol}$ of each primer, $200 \mu \mathrm{M}$ dNTPs, $1 \mathrm{U}$ of TaqDNA polymerase (Dynazyme II) and $10 \mathrm{ng}$ of template DNA. Reactions were performed in a MJ PTC-100 thermocycler (Peltier ThermalCycler, MJ Research, Waltham, Massachusetts, U.S.A.). Subsequently, $5 \mu$ l of each amplification mixture were analyzed by agarose gel electrophoresis in TAE buffer $(1.5 \% \mathrm{w} / \mathrm{v})$ containing $1 \mu \mathrm{g} / \mathrm{ml}$ ethidium bromide, by comparison with a known mass standard. After purification (Roche, Mannheim purification kit, Germany), the PCR reactions were quantified with a spectrophotometric method (Biophotometer, Eppendorf). Amplification was not successful for four monocots: Carex halleriana (Cyperaceae), Ruscus aculeatus (Asparagaceae), Simethis mattiazzii (Xanthorrhoeaceae) and Dioscorea communis (Dioscoreaceae; see Li et al., 2011 for problems in ITS amplification of Dioscorea).

Automated DNA sequencing was performed directly from the purified PCR products using BigDye Terminator v.2 chemistry and an ABI310 sequencer (PE-Applied Biosystems, Norwalk, Connecticut, U.S.A.).

Original sequences were checked for homology with Blast (http://blast.ncbi.nlm.nih.gov/Blast.cgi) and edited with BioEdit v.7.0 (Hall, 1999). The few overlapping peaks at the same 1-bp position, possibly associated with heterozygous alleles or minor DNA polymerase errors, were translated following the IUPAC ambiguity code. All original sequences were deposited in GenBank and can be retrieved using the accession number in Appendix A.

The final dataset consisted of 76 accessions of seed plants (Appendix A), including three species of respectively, Asparagaceae subfamily Nolinoideae, Xanthorrhoeaceae and Dioscoreaceae that were not present in our plots but added in order not to lose important phylogenetic information caused by the missing sequences of Ruscus, Simethis and Dioscorea. The above higher-order taxa would have been otherwise not represented. Multiple alignment of the ITS-5.8S dataset was performed with MAFFT v. 7.0 (Katoh and Standley, 2013) using the L-INS-i strategy and then carefully checked by visual inspection with BioEdit. Gaps were then coded as separate characters according to Simmons and Ochoterena (2000) using FastGap v.1.0.8 (Borchsenius, 2009), and appended at the end of the dataset. Tree construction was finally performed using Neighbor-Joining (NJ) and bootstrap analysis with 1000 replicates, as implemented in PAUP* v.4.0 (Swofford, 2000). NJ is a fast and effective method to infer reliable phylogenetic trees with branch lengths reflecting evolutionary divergence among species (Mihaescu et al., 2009), as shown by the large congruence between our tree and those by APG III (2009) in terms of topology of the major clades retrieved.

\subsection{Data analysis}

All analyses were performed with $\mathrm{R}$ software ( $\mathrm{R}$ Core Team, 2014). After checking the significance of differences in total ground cover and soil $\mathrm{pH}$ between the two forest types, we examined taxonomic diversity at three levels. Overall species richness (SR) of the pine and cork oak plots was determined ( $\gamma$-diversity), followed by the estimation of taxonomic singularity at the genus and family level as the ratios genera:species and family:genera, respectively (Ojeda et al., 2000). Third, we calculated $\beta$-diversity as the compositional dissimilarity of each plot against all the other plots of the two forest types, based on the Lennon distance measure (Lennon et al., 2001). Nonmetric multidimensional scaling (NMDS, metaMDS function; Oksanen et al., 2008) was used to visualize the compositional differences between the two forest types based on the Lennon dissimilarity index. Differences in the position of plots in the multivariate space were tested using a permutational analysis of variance (PERMANOVA) with 999 permutations (Adonis function in Vegan), followed by a multivariate dispersion homogeneity test using betadisper (Warton et al., 2012). Then, an indicator species analysis (Dufrêne and Legendre, 1997) was performed (function multipatt in Indicspecies package) to identify the species significantly associated with each of the two forest types in terms of frequency and cover. Ellemberg indicator values of these taxa for light (L), temperature (T), soil humidity $(U)$, soil reaction $(R)$ and nutrients $(\mathrm{N})$, according to Pignatti (2005), were used to infer the main ecological differences between the two forest ecosystems.

We then used Faith's phylogenetic diversity (PD) metric (Faith, 1992) to quantify the phylogenetic $\alpha$-diversity of each forest plot as the total branch length joining the basal node (i.e., the spermatophyte node) to the branch tips of all species in the plot. Faith's $\mathrm{PD}$ is the simplest measure of the cumulative evolutionary age in a community and has the advantage of being a phylogenetic diversity metric in conservation and ecological research (Faith, 1992; Forest et al., 2007; Morlon et al., 2011; Rodrigues and Gaston, 2002). We also used the Net Relatedness Index (NRI) and the Nearest Taxon Index (NTI) to quantify the degree of communityweighted phylogenetic relatedness among species within each forest plot. Both indices are useful for the assessment of genetic sustainability and health of forest ecosystems (Potter, 2008; Potter and Koch, 2014). NRI measures the standardized effect size of the mean phylogenetic distance (MPD), which estimates the average phylogenetic relatedness between all possible pairs of taxa in an assemblage (Webb, 2000). NTI is a standardized measure of the branch-tip phylogenetic clustering of the species on the plot (usually indicated as MNTD, Mean Nearest Taxon Distance), regardless of the arrangement of the higher level groups in the phylogenetic tree (Webb et al., 2002). Positive values of NRI and NTI indicate that MPD and MNTD, respectively, are lower than expected by chance (null model) and that phylogenetic clustering of species occurs. Conversely, negative values of NRI and NTI result when the observed MPD and MNTD are greater than expected by chance and thus indicate phylogenetic over-dispersion or evenness. To compare MPD and MNTD to null community data we used a simple null model of randomly drawing species (phylogeny branch tips), holding plot species richness constant as suggested in the Phylocom software (Webb et al., 2008). All phylogenetic metrics were obtained with the package Picante (Kembel et al., 2010).

The effects of forest type on taxonomic and phylogenetic diversity were finally examined using a linear model approach, also 
including canopy cover and main site characters (altitude, topography, slope aspect and inclination) as independent variables. Effects were fitted using gls from the nlme package with a Gaussian error distribution and parameter estimation via restricted maximum likelihood for the Shannon diversity index $H^{\prime}$, PD, NRI and NTI; for SR we used glm from the stats package with a Poisson error distribution, loglink and parameter estimation via maximum likelihood. Starting from the full model, we looked for optimal structure based on Akaike's Information Criterion (AIC): the model with the lowest value was considered to be most consistent with the dataset. For each model, we calculated the $R$-squared $\left(R^{2}\right)$, which refers to the fraction of the total variation in the response variable explained by the model. Moreover, differences in taxonomic and phylogenetic diversity metrics as well as environmental variables (Ellemberg values) between the two forest types were tested with the $t$-test or the non-parametric Wilcoxon signedrank test, after checking normality and homogeneity of variance.

\section{Results}

\subsection{Taxonomic diversity}

Gamma-diversity was considerably higher in the cork oak stands (76 species) than in the maritime pine stands (46). Taxonomic singularity at the genus level was also higher in the former forest type ( 0.82 vs. 0.72 ), though comparable at the family level.

The range of species number per plot was 14-23 in the cork oak and 9-17 in the pine stands, with a clear difference in the mean values (18.7 vs. 13.4 , respectively). Species richness was explained by forest type for the $54 \%$ of the total variation: It was significantly increased in the cork oak stands $(P<0.001)$. AIC criteria indicated a negligible role for the site variables and forest cover (Table 1). Lower $\alpha$-diversity in the pine plots was confirmed by Shannon values $(1.56 \pm 0.17$ vs. $1.69 \pm 0.19$ in cork oak stands, $P=0.007)$, though model results showed that this index was affected by neither forest type (only $10 \%$ of the variation), nor by the other variables included in the analysis (Table 1 ).

Looking at $\beta$-diversity, a significant difference in the mean inter-plot Lennon distance occurred between the two forest types (pine: $0.305 \pm 0.07$; cork oak: $0.396 \pm 0.06 ; P<0.001$ ), indicating larger compositional differences between cork oak plots than between pine plots. The NMDS scattergram (Fig. 2) allowed us to visualize the broader dispersion of cork oak plots and their partial separation from the more clustered pool of pine plots in the positive part of the first NMDS axis. PERMANOVA test confirmed the significance of this separation $(P=0.001)$, supporting the differences in the floristic composition of the two forest types.

Indicator species analysis revealed that 17 seed plant taxa are significantly associated with cork oak stands, belonging to five



Fig. 2. Non-metric multidimensional scaling showing compositional dissimilarity plots using the Lennon distance measure; $p_{\text {perm }}$ indicates the significance of the difference between cork oak and maritime pine plots, based on PERMANOVA with 999 permutations; $p_{\text {disp }}$ indicates the significance of the dispersion effect.

main growth forms: Four trees, three shrubs, six vines, two herbs and two graminoids (Fig. 3). Only six indicator species resulted for pine stands, of which one was a tree, three were shrubs and two were graminoids (Fig. 3); neither herbs nor vines included indicator species in this forest type. Interestingly, some indicator taxa of cork oak stands such as the geophytic herb Cyclamen repandum, the vine Asparagus acutifolius or the shrub Cytisus villosus were nearly completely lacking in the pine stands (Fig. 3). Indicator species of pine plots had higher light requirements (mean L value $=8.2$ vs. 4.9 ) and were more distinctly xerophilous (mean $\mathrm{U}$ value $=2.25$ vs. 3.67 ), acidophilus (mean $\mathrm{R}$ value $=2.8$ vs. 5.2 ), and with lower nutrient requirements (mean $\mathrm{N}$ value $=2.2$ vs. 4.3; Fig. 4).

\subsection{Phylogenetic diversity and structure}

The ITS-5.8S alignment included 1502 positions of which 857 were phylogenetically informative. The resulting tree (total length =9148) was largely congruent with the APG III tree for the major angiosperm groups (Fig. 3). Monocots and eu-dicots, both monophyletic clades, included members of 4 and 18 orders of the APG system, respectively; within the eu-dicots, Ranunculales were sister to the major clades of Asterids and Rosids. As many as seven dicot orders (Sapindales, Malpighiales, Santalales, Caryophyllales, Geraniales, Aquifoliales, Ranunculales) were only represented in the cork oak plots; all other orders were represented in both forest types. The range of PD values was 24614623 and 3215-5283 in pine and cork oak forests, respectively, and linear regression supported a positive correlation with species

Table 1



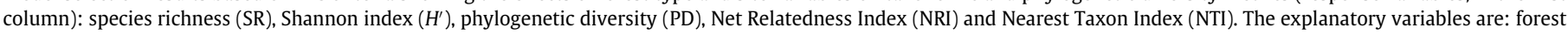

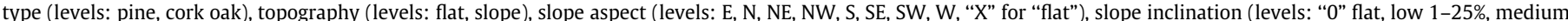

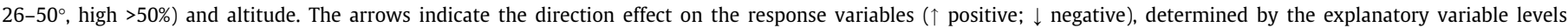

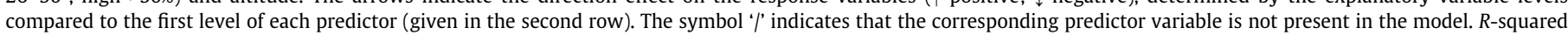
$\left(R^{2}\right)$ values and degrees of freedom (df) are given.

\begin{tabular}{|c|c|c|c|c|c|c|c|}
\hline \multirow[t]{2}{*}{ Response variable } & \multirow[t]{2}{*}{ Forest type } & \multirow{2}{*}{$\begin{array}{l}\text { Topography } \\
\text { Level: flat }\end{array}$} & \multirow{2}{*}{$\begin{array}{l}\text { Slope aspect } \\
\text { Level: est }\end{array}$} & \multirow{2}{*}{$\begin{array}{l}\text { Slope inclination } \\
\text { Level: } 0\end{array}$} & \multirow[t]{2}{*}{ Altitude } & \multirow[t]{2}{*}{$\mathrm{df}$} & \multirow[t]{2}{*}{$R^{2}$} \\
\hline & & & & & & & \\
\hline SR & $\uparrow$ Cork oak forest & 1 & 1 & 1 & 1 & 64 & 0.54 \\
\hline$H^{\prime}$ & $\uparrow$ Cork oak forest & 1 & 1 & 1 & I & 64 & 0.107 \\
\hline PD & $\uparrow$ Cork oak forest & $\downarrow$ Slope & $\begin{array}{l}\downarrow N, N E, N W, S E, W, S, S W, X \\
\uparrow S, S W\end{array}$ & 1 & $\downarrow$ Altitude & 54 & 0.486 \\
\hline NRI & $\uparrow$ Cork oak forest & 1 & I & $\begin{array}{l}\downarrow \text { High } \\
\uparrow \text { Low, medium }\end{array}$ & $\downarrow$ Altitude & 52 & 0.502 \\
\hline NTI & $\uparrow$ Cork oak forest & 1 & 1 & i & 1 & 64 & 0.635 \\
\hline
\end{tabular}






Fig. 3. Neighbor-Joining phylogenetic tree of the seed plant species recorded in the 66 plots, based on ITS-5.8 DNA sequences. Major angiosperm clades and orders are indicated according to the APG III system; bootstrap support (BS) > 50\% is shown. For each species (branch-tips), the frequency \% in pine vs. cork oak plots are given, and those significantly associated with one of the two forest types, as resulting from Indicator species Analysis, are indicated in bold (in italics those of cork oak forest, in plain those of pine forest): ${ }^{* * *} P<0.001$; ${ }^{* *} P<0.005 ;{ }^{*} P<0.01$. The graminoid Carex halleriana, not shown in the tree, was associated to pine stands $(P<0.01)$.

richness $(r=0.89, F=279.9, P<0.001$; Fig. 5a), genus richness $(r=0.91 ; F=322, \quad P<0.01 ;$ Fig. $5 b)$ and species diversity $H^{\prime}$ $(r=0.51, F=22.57, P<0.001$; Fig. $5 \mathrm{c})$. Model results (Table 1) showed that forest type is the strongest predictor for PD $(P<0.001)$, and that this metric is also affected by site variables such as topography (positive effect of flat vs. slope; $P=0.016$ ), 
slope aspect (positive effect of $S$ - and W-facing slopes; $P=0.474$ ) and altitude (negative effect of increasing altitude; $P=0.014$ ); no effect of forest cover was detected.

All plots had negative values of the NRI metric (Supplementary material; Fig. 6), indicating that species were more distantly related than expected by chance in both forest types. However, in only a small proportion of pine plots $(2,6.1 \%)$ phylogenetic over-dispersion was statistically significant $(P<0.05)$, while it was significant for a considerably higher proportion of cork oak plots $(13,39.4 \%)$

Looking at the NTI metric (Supplementary material; Fig. 6), the pine plots resulted mostly positive (only four negative values, $12.1 \%)$, and none deviated significantly from the expected range of values. Cork oak plots were instead mostly negative (27, $81.8 \%$ ), with 18 of them (54.5\%) significantly deviating from the expected range and therefore including species more distantly related to each other than expected by chance. Model results showed that cork oak forest positively affected both NRI and NTI (both $P<0.001$ ). However, variation of NTI was explained by the forest type only (63\%), while NRI was partly affected also by site variables, especially slope inclination $(P=0.008)$ and altitude $(P=0.085$; Table 1$)$.

\section{Discussion}

Conversion of the native sclerophyllous communities into second-generation stands of non-native maritime pine populations had a strong negative impact on the taxonomic and phylogenetic diversity of the local forest flora. Overall species richness in pine forests was $40 \%$ lower than in the cork oak stands, while at the plot level there was a reduction of $28.5 \%$ (on average ca. 5 species less). This result is in line with other studies showing reduction of species richness in forest ecosystems invaded by non-native trees and shrubs (González-Muñoz et al., 2012; Lorenzo et al., 2012). In terms of functional groups, this decrease was especially strong for the herbaceous plants, both geophytes and hemicryptophytes. When considering species abundance, reduction of Shannon diversity was less dramatic (19.1\%) and non-significant according to the model results, probably due to the positive effect of a higher species evenness in the shrub and understory layers of the pine stands. Taxonomic singularity at the genus level was also lower than in cork oak stands, though at a higher level there were no negative effects. Apparently, major lineages such as families were less affected by community composition and forest type than lowerrank and younger evolutionary units such as species and genera. Compositional dissimilarities among cork oak plots were on average distinctly larger than among pine plots, indicating that pine stands induce floristic homogenization and reduction of $\beta$ diversity at the landscape level. Only three monocot species were exclusively found in the latter forest type, showing its limited contribution to the regional plant diversity.

Overall, these findings support evidence from other studies showing that non-native pine woodlands have a negative impact on the diversity and distinctness of the local flora (e.g., Chiarucci and De Dominicis, 1995; Mazurek and Romane, 1986; Ojeda et al., 2000). This explains why in large areas of Mediterraneantype shrublands of the southern hemisphere, several Pinus species (e.g., $P$. pinaster, $P$. radiata) are considered as problematic invasive aliens causing severe shifts in plant life-form dominance and reducing diversity (Richardson et al., 1994). In the present study, the mosaic-like pattern of distribution of the two forest types and their occurrence under the same climate and parent rock suggests that species loss in the pine forest is driven by ecological changes at the stand level, among which are light and soil conditions. Lower light availability caused by afforestation with pine



Fig. 4. Mean and standard errors of Ellemberg indicator values (after Pignatti, 2005) for light $(\mathrm{L})$, temperature $(\mathrm{T})$, soil humidity $(\mathrm{U})$, reaction $(\mathrm{R})$ and nutrients $(\mathrm{N})$ of indicator species of cork oak and maritime stands; indicator species are shown in Fig. 3. All differences are significant (L: $P<0.001 ; \mathrm{U}, \mathrm{R}, \mathrm{N}: P<0.05$ ), except for temperature (n.s.).

can reduce the diversity of tree-less, open vegetation types as heathlands and garrigues (Ojeda et al., 2000) but would be expected to have a negligible influence on forested habitats due to minor differences in canopy cover, as in the present study. However, Ellemberg values showed higher light requirements for the pine indicator species, which may take advantage of the young, post-fire origin of the stands and persist for several years under the relatively sparse cover of this conifer, until the canopy closes. Variations in the soil environment are likely to play a more important role than light. It is well documented that the thick layer of needle-litter of pines and other conifers has chemical and physical effects such as increased acidity and consequent loss of fertility due to the low quality in terms of low leaf nutrient concentrations and high C and lignin concentrations (Augusto et al., 2002; Binkley and Giardina, 1998). Indeed, Ellemberg values of indicator species supported the marked acidophytic-oligotrophic nature of the pine forest soil, in line with the lower soil $\mathrm{pH}$ values directly measured in this study (Supplementary material).

Loss of taxonomic diversity in the pine stands implied a parallel reduction of phylogenetic diversity, which confirms recent evidence showing the impact of invading tree species on Mediterranean plant communities (Lapiedra et al., 2015; Constán-Nava et al., 2015). As found in previous studies in different areas and ecosystems (Forest et al., 2007; Qian et al., 2014) these indices were distributed in a similar manner and positively associated (Fig. 5), which explains why a debate exists about the usefulness of PD vs. taxon richness in, for example, the selection of areas or ecosystems to be protected in conservation actions (Winter et al., 2013). According to Forest et al. (2007), however, the correspondence between taxon richness and PD can sometimes hide a fundamental decoupling of these biodiversity indices, and deviations of evolutionary diversity from expectations based on the number of species can occur in various plant assemblages (Knapp et al., 2008), including forest communities (Potter and Woodall, 2012, 2014). Though this was not apparently the case in our model system, the use of PD was still meaningful as this index provided a measure of the evolutionary variations associated with the loss of species. Based on present findings, these variations can be predicted and monitored using SR, which may assist the planning of management actions aiming at the re-conversion of pine stands to cork oak stands. 

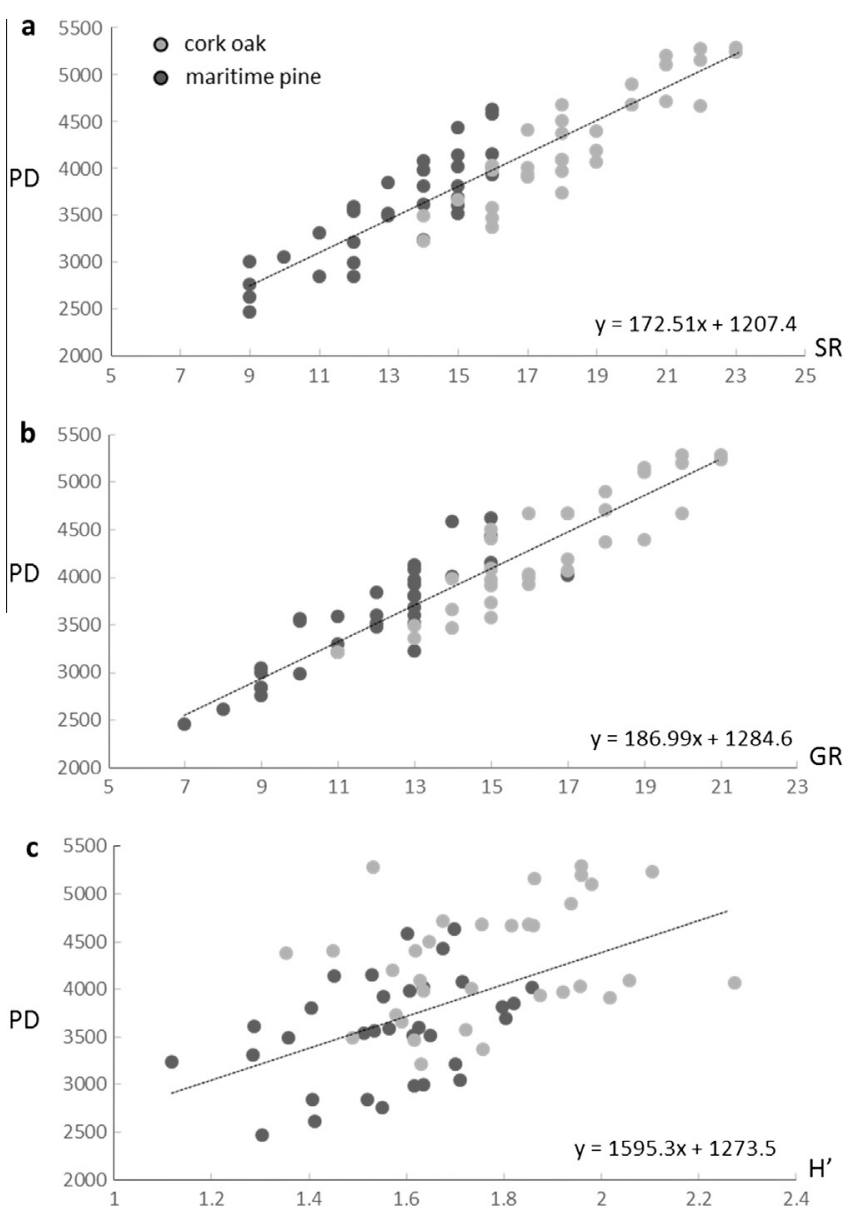

Fig. 5. Relationships between phylogenetic diversity (PD) and (a) species richness (SR), (b) genus richness (GR) and (c) Shannon diversity $\left(H^{\prime}\right)$ in the cork oak and maritime stands.

In addition, species richness-independent metrics such as NRI and NTI also demonstrated significant differences in the amount of evolutionary diversity contained in the two forest communities and differences in their phylogenetic structure (Fig. 6). Model results showed that cork oak forest had a positive effect on both indices and, consequently, that conversion into pine forest led to an increase of phylogenetic clustering of the community. This effect was stronger for NTI and not dependent on other site

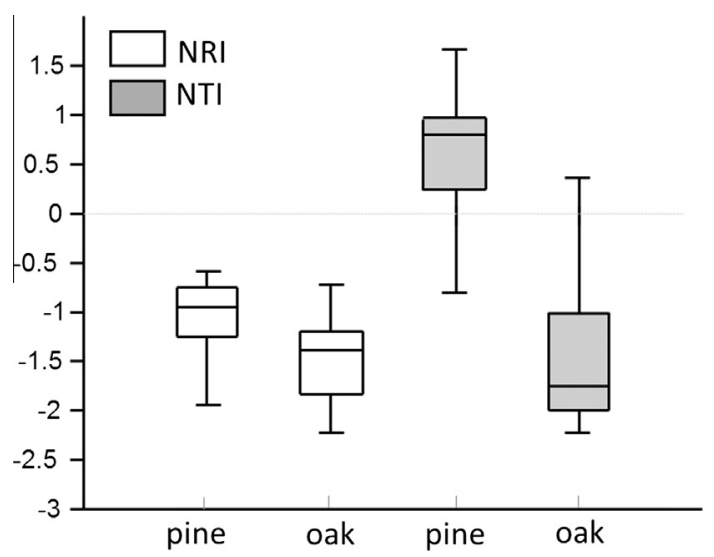

Fig. 6. Box-plots showing mean values and range of variation of the NTI and NRI metrics of phylogenetic diversity in the cork oak and maritime pine stands. Differences for both indexes are significant at $P$-level $<0.001$. variables such as altitude and slope inclination as in the case of NRI. Based on the latter indicator, both forest types resulted over-dispersed but significant deviations from expected values occurred in the cork oak stands only. This was supported by the NTI index, which showed over-dispersion only in the latter forest type, with few exceptions for the pine stands. Because of the different properties of the two indices (NRI estimating the average phylogenetic relatedness between all possible pairs of taxa in an assemblage, NTI being a standardized measure of the branch-tip phylogenetic clustering of the species on the plot, regardless of the arrangement of the higher level groups in the phylogenetic tree), this response suggests that loss of evolutionary diversity in the pine forest is stronger in terms of fine-scale relatedness between younger taxa such as species (the branch-tips of the tree). This is in line with the changes in taxonomic singularity mentioned above, supporting that negative effects are less dramatic when considering relatedness at deeper levels (measured by NRI), thus including the evolutionarily older taxa. Phylogenetic overdispersion in the cork oak forest results from the co-existence of distantly related taxa that may have converged on a similar niche-use and show phenotypic attraction, as predicted for different ecosystem types (Cavender-Bares et al., 2004; Webb et al., 2002). As often in harsh environments (Kelly, 1999), higher clumping in the pine forest is instead likely associated with a stronger "habitat filtering" effect by which plant species that are more closely related than expected by chance tend to coexist because of their similar ecological requirements (under the assumption of phylogenetic niche conservatism; Webb et al., 2002). The selective conditions that characterize the maritime pine stands in terms of soil acidity and oligotrophy have likely enhanced this effect, with consequent exclusion of several species of the cork oak habitat. One of them is, for example, the shrub C. villosus, a nitrogenfixing member of the broom genus (Watt et al., 2003; Carrari et al., 2015), whose strong decline in the pine stands may have significantly contributed to the nutritional impoverishment of the soil. Hence, the habitat filtering effect has likely resulted in the proportional increase of evolutionarily related taxa with acidtolerance specialization such as the Ericaceae.

This example shows that the selection of particular lineages with elevated competitive ability under changed environmental conditions could lead to a decrease in phylogenetic dispersion and, in turn, diversity of functional traits (Mayfield et al., 2010), which may have serious consequences for the maintenance of ecosystem processes at an ecologically relevant timescale (Cadotte et al., 2011; Srivastava et al., 2012). Evolutionarily distinct species are especially expected to contribute to the diversity of traits within forest ecosystems, which might convey numerous benefits to their stability and resilience in the face of environmental changes (Potter and Koch, 2014; Potter and Woodall, 2012, 2014). According to Winter et al. (2013), however, whether phylogenetic diversity correlates with functional diversity depends on the considered traits, the level of their phylogenetic conservatism, and the focal taxa and regions. Hence, direct analyses of functional traits are required to better understand their impact on assembly processes and phylogenetic structure, as well as a careful testing of niche conservatism (i.e., phylogenetic signal of functional traits) among sclerophyllous woodlands.

\section{Conclusions}

Combining plant community analysis with appropriate phylogenetic and molecular techniques to generate DNA sequences from local plant material may improve the resolution and reliability of the trees depicting the evolutionary relationships within forest communities. By using this approach we contributed to the genetic 
knowledge of the rich Mediterranean forest flora, which is still largely fragmentary (Scarascia et al., 2000). Also, we showed that the impact of pine invasion goes beyond the reduction of the taxonomic diversity in our model system, as this process also involves the alteration of the phylogenetic structure of the native seed plant assemblage. To our knowledge this effect was not described before, at least in similar ecosystems.

Under the assumption that conservation of taxonomic, phylogenetic and functional diversity is a priority to ensure the integrity and stability of forests, our findings support the active management of the pine stands to promote their gradual re-conversion to oak-dominated woodlands. The occurrence of seedlings of the cork oak and other Quercus species in the understory and shrub layers of these stands (see Fig. 3 for their frequency) shows that native trees are not excluded by the selective soil conditions, and therefore that the key starting point for a natural re-conversion already exists. Progressive thinning of the pine trees will likely increase the competitive ability of the young oak trees as they grow up, because of their high light requirement (Pausas et al., 2009). In the long-term, such strategy will likely reduce the spatial fragmentation of cork oak areas and promote the re-establishment of the original habitat conditions, especially soil, thus potentially opening the way to the recovery of the associated biodiversity components that suffered more the spread of the pine, such as herbs and vines. Thanks to the mosaic-like distribution of the two forest types and their intimate spatial interconnections, recovery can be expected to take place by seed dispersal from the surrounding populations, though this may require decades for some species. On the contrary, further soil acidification that would result from the persistence of the pine stands may enhance species loss in the longer term, because species richness in artificial conifer woodlands generally decreases with soil pH (Verstraeten et al., 2013). Recolonization will likely promote the recovery of the taxonomic diversity and over-dispersed phylogenetic structure of the community, favoring the conservation and restoration of a vanishing Mediterranean forest ecosystem.

\section{Acknowledgments}

Authors wish to thank the staff of "Corpo Forestale dello StatoUfficio Territoriale per la Biodiversità" of Follonica (Grosseto), and the staff of "Unione dei Comuni" of Massa Marittima for providing information on the distribution and current management of the maritime pine and cork oak forest areas. The comments of two anonymous reviewers contributed significantly to prepare the final version of the manuscript. Research grants to FS and AC from the Ministry of University and Scientific Research (MIUR), and University of Florence are acknowledged.

\section{Appendix A}

List of seed plants (excluding ferns) recorded in the pine and cork oak plots, with GenBank accession numbers used for tree construction and subsequent calculation of phylogenetic diversity metrics. Originally sequenced taxa are in bold; for these species vouchers details are given. Plant nomenclature follows Selvi (2010).

\footnotetext{
Anthericum liliago L.; Italy, Tuscany, Casal di Pari, Selvi $\mathcal{E}$ Coppi no. 3581 (FI), LN871589 - Arbutus unedo L.; AF091952 - Asparagus acutifolius L.; Italy, Tuscany, Sticciano, Selvi no. 3506 (FI), LN871590 - Brachypodium retusum (Pers.) P. Beauv.; JN187622 - Brachypodium rupestre (Host) Roem. \&Schult.; AF019806 - Brachypodium sylvaticum (Huds.) P.
}

Beauv.; GQ373321 - Bromus erectus Huds.; AY367907 Calluna vulgaris (L.) Hull; HM854157 - Carex distachya Desf.; GU176156 - Carex flacca Schreb.; DQ998915 - Carex olbiens Jord.; AY278282 - Cistus creticus L.; DQ092936 Cistus salvifolius L.; Italy, Tuscany, Sticciano, Selvi no. 3582 (FI), LN871591 - Clematis flammula L.; Italy, Tuscany, Sticciano, Selvi no. 3584 (FI), LN871592 - Crocus etruscus Parl.; HG518183 - Cyclamen repandum Sm.; AM990484 Cynosurus echinatus L.; AF532937 - Cytisus scoparius (L.) Link; AF351122 - Cytisus villosus Pourr.; AF443639 Danthonia decumbens (L.) DC.; EU401308 - Daphne gnidium L.; AJ549491 - Erica arborea L.; HQ858911 - Erica scoparia L.; AY520803 - Fraxinus ornus L.; EU314870 - Genista germanica L.; ITS1-5.8S: AJ699002; ITS2: AJ699003 Genista pilosa L.; AY263655 - Geranium robertianum L.; DQ525071 - Hedera helix L.; AF551729 - Hieracium racemosum W. et K.; Italy, Tuscany, Sticciano, Selvi no. 3423 (FI), LN871593 - Hypericum australe Ten.; Italy, Tuscany, Civitella Marittima, Selvi \& Coppi no. 3519 (FI), LN871594 - Hypochoeris glabra L.; AY504692 - Ilex aquifolium L.; FJ394658 - Juniperus communis L.; EU277677 - Lavandula stoechas L.; JF301409 - Limodorum abortivum (L.) Sw.; AY351378 - Lonicera implexaAiton; FJ217861 Luzula forsteri (Sm.) DC.; FJ873796 - Melica arrecta Kuntze; Italy, Tuscany, Civitella Marittima, Selvi no. 3580 (FI), LN871595 - Moehringia trinervia (L.) Clairv.; DQ901461 - Molinia coerulea (L.) Moench; AF019857 - Myrtus communis L.; JN660890 - Osyris alba L.; EF569287 Phillyrea angustifolia L.; JX862624 - Phillyrea latifolia L.;

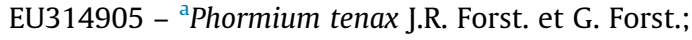
AY177605 - Physospermum cornubiense (L.) DC.; AF077904 - Pinus pinaster Ait.; AF037024 - Pistacia lenstiscus L.; DQ390467 - ${ }^{\mathrm{b}}$ Polygonatum verticillatum (L.) All.; JF977846 Prunella vulgaris L.; JQ669130 - Prunus spinosa L.; AF318730 - Pulicaria odora (L.) Rchb.; HE602393 - Pyrus spinosa Forssk.; EU150019 - Quercus cerris L.; AY226833 - Quercus ilex L.; AY226837 - Quercus petraea (Matt.) Liebl.; AY226838 - Quercus pubescens Willd.; AY226846 - Quercus suber L.; EF581312 - Ranunculus paludosus Poir.; AY680102 - Rosa canina L.; FM164423 - Rosa sempervirens L.; AB048595 - Rubia peregrina L.; HE602427 - Rubus ulmifolius Schott; AF055792 - Serratula tinctoria L.; ITS15.8S: AF021158; ITS2: AY012336 - Smilax aspera L.; KF782918 - Solidago virgaurea L.; EU125358 - Sonchus bulbosus (L.) N. Kilian \& Greuter; AJ633302 - Sorbus domestica L.; Italy, Tuscany, Castello di Spannocchia, Selvi, S. no. (FI), LN871596 - Sorbus torminalis (L.) Crantz; AF186533 - Stachys officinalis (L.) Trevis.; JF330306 ${ }^{\mathrm{C}}$ Taccha canthrieri André; JF978861 - Teucrium scorodonia L.; JN575430 - Tuberaria lignosa (Sweet) Samp.; Italy, Tuscany, Roccastrada, Selvi \& Coppi 3583 (FI), LN871597 Viburnum tinus L.; HM563799 - Vincetoxicum hirundinaria Medik.; AJ320474

\footnotetext{
a Replacing Simethis mattiazzi (Vand.) Sacc. (Xanthorrhoeaceae).

b Replacing Ruscus aculeatus L. (Asparagaceae subfam. Nolinoideae).

c Replacing Dioscorea communis (L.) Caddick \& Wilkin (Dioscoreaceae).
}

\section{Appendix B. Supplementary material}

Supplementary data associated with this article can be found, in the online version, at http://dx.doi.org/10.1016/j.foreco.2016.02. 013. 


\section{References}

Agostini, R., 1968. Revisione dell'areale italiano del Pino marittimo (Pinus pinaster Aiton). Arch. Bot. Biogeogr. Ital. 44, 184-202.

Andrés, C., Ojeda, F., 2002. Effects of afforestation with Pinus pinaster on biodiversity of Mediterranean heathlands in South Spain. Biodivers. Conserv. 11, 15111520.

Apg, I.I.I., 2009. An update of the Angiosperm Phylogeny Group classification for the orders and families of flowering plants: APG III. Bot. J. Linn. Soc. 161, 105-121.

Aronson, J., Pereira, J.S., Pausas, J.G., 2009. Cork Oak Woodlands on the Edge. Island Press, Washington, Covelo, London.

Arroyo Rodríguez, V., Cavender-Bares, J., Escobar, F., Melo, F.P.L., Tabarelli, M., Santos, B.A., 2012. Maintenance of tree phylogenetic diversity in a highly fragmented rain forest. J. Ecol. 100, 702-711.

Augusto, L., Ranger, J., Binkley, D., Rothe, A., 2002. Impact of several common tree species of European temperate forests on soil fertility. Ann. For. Sci. 59, 233253.

Berrahmouni, N., Regato, P., Ellatifi, M., Daly-Hassen, H., Bugalho, M., Bensaid, S., Díaz, M., Aronson, J., 2009. Ecoregional planning for biodiversity conservation. In: Aronson, J., Pereira, J.S., Pausas, J.G. (Eds.), Cork Oak Woodlands on the Edge. Island Press, Washington, Covelo, London, pp. 203-216.

Binkley, D., Giardina, C., 1998. Why do tree species affect soils? The warp and woof of tree-soil interactions. Biogeochemistry 42, 89-106.

Borchsenius, F., 2009. FastGap, version 1.2. Department of Biological Sciences, University of Aarhus, Denmark http://192.38.46.42/aubot/fb/FastGap_home. htm.

Cadotte, M.W. et al., 2011. Beyond species: functional diversity and the maintenance of ecological processes and services. J. Appl. Ecol. 48, 1079-1087.

Carrari, E., Ampoorter, E., Coppi, A., Selvi, F., 2015. Diversity of secondary woody species in relation to species richness and cover of dominant trees in thermophilous deciduous forests. Scand. J. Forest Res. http://dx.doi.org/ 10.1080/02827581.2015.1081981.

Cavender-Bares, J., Ackerly, D.A., Baum, D., Bazzaz, F.A., 2004. Phylogenetic overdispersion in Floridian oak communities. Am. Nat. 163, 823-843.

Chiarucci, A., De Dominicis, V., 1995. Effects of pine plantations on ultramafic vegetation of Central Italy. Isr. J. Bot. 43, 7-20.

Constán-Nava, Soliveres, S., Torices, R., Serra, L., Bonet, A., 2015. Direct and indirect effects of invasion by the alien tree Ailanthus altissima on riparian plant communities and ecosystem multifunctionality. Biol. Invasions 17, 1095-1108.

Coppi, A., Mengoni, A., Selvi, F., 2008. AFLP fingerprinting of taxa of Anchusa endemic to the Corso-Sardinian system: genetic diversity and differentiation of an insular endemic group threatened with extinction. Biol. Conserv. 141, 2000 2011

Corine Biotopes Manual, 1991. Habitats of the European Community, Brussels.

Doyle, J.J., Doyle, J.L., 1990. Isolation of plant DNA from fresh tissue. Focus 12, 13 15.

Dufrêne, M., Legendre, P., 1997. Species assemblages and indicator species: the need for a flexible asymmetrical approach. Ecol. Monogr. 67, 345-366.

Faith, D.P., 1992. Conservation evaluation and phylogenetic diversity. Biol. Conserv. $61,1-10$.

Faith, D.P. et al., 2010. Evosystem services: an evolutionary perspective on the links between biodiversity and human well-being. Curr. Opin. Environ. Sustain. 2, 66-74.

Feliner, G.N., Rosselló, J., 2007. Better the devil you know? Guidelines for insightful utilization of nrDNA ITS in species-level evolutionary studies in plants. Mol. Phylogenet. Evol. 44, 911-919.

Fernandes, P.M., Rigolot, E., 2007. The fire ecology and management of maritime pine (Pinus pinaster Ait.). For. Ecol. Manage. 241, 1-13.

Forest, F., Grenyer, R., Rouget, M., Davies, T.J., Cowling, R.M., Faith, D.P., 2007. Preserving the evolutionary potential of floras in biodiversity hotspots. Nature 445, 757-760.

Gabellini, A., De Dominicis, V., 2003. Caratteristiche ecologiche delle pinete di pino marittimo dell'area Farma-Merse e spunti per una futura gestione. Parlatorea 6 , $163-170$.

González-Muñoz, N., Costa-Tenorio, M., Espigares, T., 2012. Invasion of alien Acacia dealbata on Spanish Quercus robur forests: impact on soils and vegetation. For. Ecol. Manage. 269, 214-221.

Hall, T.A., 1999. BioEdit: a user-friendly biological sequence alignment editor analysis program for windows 95/98/NT. Nucl. Acids Symp. Ser. 41, 95-98.

Hollingsworth, P.M., Graham, S.W., Little, D.P., 2011. Choosing and using a plant DNA barcode. PLoS ONE 6 (5), e19254. http://dx.doi.org/10.1371/journal. pone.0019254.

Jose, S., Kohli, R.K., Singh, H.P., Batish, D.R., Pieterson, E.C., 2008. Invasive plants: a threat to the integrity and sustainability of forest ecosystems. In: Kohli, R.K., Jose, S., Singh, H.P., Batish, D.R. (Eds.), Invasive Plants and Forest Ecosystems. CRC Press, Boca Raton, pp. 3-11.

Jump, A.S., Marchant, R., Penuelas, J., 2009. Environmental change and the option value of genetic diversity. Trends Plant Sci. 14, 51-58.

Katoh, K., Standley, D.M., 2013. MAFFT multiple sequence alignment software version 7: improvements in performance and usability. Mol. Biol. Evol. 30, 772780 .

Kelly, C.K., 1999. On the relationship between function and phylogenetic relatedness: environmental severity and community structure. XVI Intl. Botan. Congr. (Abstr.).
Kembel, S.W., Cowan, P.D., Helmus, M.R., Cornwell, W.K., Morlon, H., Ackerly, D.D. 2010. Picante: $\mathrm{R}$ tools for integrating phylogenies and ecology. Bioinformatics 26, 1463-1464.

Kent, M., Coker, P., 1992. Vegetation Description and Analysis. A Practical Approach. CRC Press, Boca Raton.

Knapp, S., Kühn, I., Schweiger, O., Klotz, S., 2008. Challenging urban species diversity: contrasting phylogenetic patterns across plant functional groups in Germany. Ecol. Lett. 11, 1054-1064.

Lapiedra, O., Sol, D., Traveset, A., Vilà, M., 2015. Random processes and phylogenetic loss caused by plant invasions. Global Ecol. Biogeogr. 24, 774-785.

Lennon, J.J., Koleff, P., Greenwood, J.J.D., Gaston, K.J., 2001. The geographical structure of British bird distributions: diversity, spatial turnover and scale. J. Anim. Ecol. 70, 966-979.

Li, D.-Z. et al., 2011. Comparative analysis of a large dataset indicates that internal transcribed spacer (ITS) should be incorporated into the core barcode for seed plants. Proc. Natl. Acad. Sci. U.S.A. 49, 19641-19646.

Lorenzo, P., Pazos-Malvido, E., Rubido-Bará, M., Reigosa, M.J., González, L., 2012 Invasion by the leguminous tree Acacia dealbata (Mimosaceae) reduces the native understorey plant species in different communities. Aust. J. Bot. 60, 669675.

Mayfield, M.M., Bonser, S.P., Morgan, J.W., Aubin, I., McNamara, S., Vesk, P.A., 2010 What does species richness tell us about functional trait diversity? Predictions and evidence for responses of species and functional trait diversity to land-use change. Global Ecol. Biogeogr. 19, 423-431.

Mazurek, H., Romane, F., 1986. Dynamics of young Pinus pinaster vegetation in a mediterranean area: diversity and niche-strategy. Vegetatio 66, 27-40.

Mihaescu, R., Levy, D., Pachler, L., 2009. Why neighbour-joining works. Algorithmica $59,1-24$

Morlon, H., Schwilk, D.W., Bryant, J.A., Marquet, P.A., Rebelo, A.G., Tauss, C., 2011. Spatial patterns of phylogenetic diversity. Ecol. Lett. 14, 141-149.

Ojeda, F., Marañón, T., Arroyo, J., 2000. Plant diversity patterns in the Aljibe mountains (S. Spain): a comprehensive account. Biodivers. Conserv. 9, 1323 1343.

Oksanen, J. et al., 2008. Vegan: Community Ecology Package. R Package Version 1.13-1. <http://vegan.r-forge.r-project.org>.

Palahi, M., Mavsar, R., Gracia, C., Birot, Y., 2008. Mediterranean forests under focus. Int. For. Rev. 10, 676-688.

Pausas, J.P., Maranon, T., Caldeira, M., Pons, J., 2009. Natural regeneration. In: Aronson, J., Pereira, J.S., Pausas, J.G. (Eds.), Cork Oak Woodlands: Ecology Adaptive Management and Restoration of an Ancient Mediterranean Ecosystem. Island Press, Washington, DC, pp. 115-124.

Pereira, J.S., Pausas, J.G., Aronson, J., 2009. Cork oak trees and woodlands. In: Aronson, J., Pereira, J.S., Pausas, J.G. (Eds.), Cork Oak Woodlands: Ecology, Adaptive Management and Restoration of an Ancient Mediterranean Ecosystem. Island Press, Washington, DC, pp. 7-9.

Pignatti, S., 2005. Valori di Bioindicazione delle piante vascolari della Flora d'Italia. Braun-Blanquetia 39, 1-97.

Potter, K.M., 2008. From genes to ecosystems: measuring evolutionary diversity and community structure with Forest Inventory and Analysis (FIA) data. In: McWilliams, W., Moisen, G., Czaplewski, R. (Eds.), comps. 2008. 2008 Fores Inventory and Analysis (FIA) Symposium; October 21-23, 2008; Park City, UT. Proc. RMRS-P-56CD. Fort Collins, CO, US.

Potter, K.M., Koch, F.H., 2014. Phylogenetic community structure of forests across the conterminous United States: regional ecological patterns and forest health implications. For. Sci. 60, 851-861.

Potter, K.M., Woodall, C.W., 2012. Trends over time in tree and seedling phylogenetic diversity indicate regional differences in forest biodiversity change. Ecol. Appl. 22, 517-531.

Potter, K.M., Woodall, C.W., 2014. Does biodiversity make a difference? Relationships between species richness, evolutionary diversity and aboveground live tree biomass across U.S. forests. For. Ecol. Manage. 321, 117-129.

Purvis, A., Agapow, P.M., Gittleman, J.L., Mace, G.M., 2000. Nonrandom extinction and the loss of evolutionary history. Science 288, 328-330.

Qian, H., Hao, Z., Zhang, J., 2014. Phylogenetic structure and phylogenetic diversity of angiosperm assemblages in forests along an elevational gradient in Changbaishan, China. J. Plant Ecol., 1-14 http://dx.doi.org/10.1093/jpe/rtt072.

Quézel, P.. Médail, F., 2003. Écologie et biogeographie des forêts du basin méditerranéen. Elsevier, Paris.

R Core Team, 2014. R: A Language and Environment for Statistical Computing. R Foundation for Statistical Computing, Vienna, Austria. <www.R-project.org>.

Richardson, D.M., Williams, P.A., Hobbs, R.J., 1994. Pine invasions in the Southern Hemisphere: determinants of spread and invadability. J. Biogeogr. 21, 511-527.

Rodrigues, A.S.L., Gaston, K.J., 2002. Maximising phylogenetic diversity in the selection of networks of conservation areas. Biol. Conserv. 105, 103-111.

Scarascia, G., Oswald, H., Piussi, P., Radoglu, K., 2000. Forests of the Mediterranean region: gaps in knowledge and research needs. For. Ecol. Manage. 132, 97-109.

Selvi, F., 2009. Site profile 9.1: Maremma, Italy. In: Aronson, J., Pereira, J.S., Pausas, J G. (Eds.), Cork Oak Woodlands: Ecology, Adaptive Management and Restoration of an Ancient Mediterranean Ecosystem. Island Press, Washington, DC, pp. 112 113.

Selvi, F., 2010. A critical checklist of the vascular flora of Tuscan Maremma. Fl Medit. 20, 47-139.

Selvi, F., Valleri, M., 2012. Cork oak woodlands in the north Tyrrhenian area: distribution and plant species diversity of a relict forest ecosystem. Biodivers. Conserv. 21, 3061-3078. 
Selvi, F., Viciani, D., 1999. Contributo alla conoscenza delle sugherete toscane. Parlatorea 3, 45-63.

Simmons, M.P., Ochoterena, H., 2000. Gaps as characters in sequence-based phylogenetic analyses. Syst. Biol. 49, 369-381.

Srivastava, D.S., Cadotte, M.W., MacDonald, A.A.M., Marushia, R.G., Mirotchnicket, N., 2012. Phylogenetic diversity and the functioning of ecosystems. Ecol. Lett. $15,637-648$.

Swofford, D.L., 2000. PAUP* 4.0: Phylogenetic Analysis using Parsimony (*and other methods), Version 4.0. Sinauer, Sunderland, Massachusetts.

Tabacchi, G., De Natale, F., Di Cosmo, L., Floris, A., Gagliano, C., Gasparini, P., Genchi, L., Scrinzi, G., Tosi, V., 2007. Le stime di superficie 2005. Prima parte. Inventario Nazionale delle Foreste e dei Serbatoi Forestali di Carbonio (INFC). MiPAF, Corpo Forestale Stato, Trento.

Verstraeten, G., Baeten, L., De Frenne, P., Vanhellemont, M., Thomaes, A., Boonen, W. Muys, B., Verheyen, K., 2013. Understorey vegetation shifts following the conversion of temperate deciduous forest to spruce plantation. For. Ecol. Manage. 289, 363-370.

Warton, D.I., Wright, S.T., Wang, Y., 2012. Distance-based multivariate analyses confound location and dispersion effects. Methods Ecol. Evol. 3, 89-101.
Watt, M.A., Clinton, P.W., Whitehead, D., Richardson, B., Mason, E.G., Leckie, A.C. 2003. Above-ground biomass accumulation and nitrogen fixation of broom (Cytisus scoparius L.) growing with juvenile Pinus radiata on a dryland site. For. Ecol. Manage. 184, 93-104.

Webb, C.O., 2000. Exploring the phylogenetic structure of ecological communities: an example for rain forest trees. Am. Nat. 156, 145-155.

Webb, C.O., Ackerly, D.D., McPeek, M.A., Donoghue, M.J., 2002. Phylogenies and community ecology. Annu. Rev. Ecol. Evol. Syst. 33, 475-505.

Webb, C.O., Ackerly, D.D., Kembel, S.W., 2008. Phylocom: Software for the analysis of phylogenetic community structure and trait evolution. Bioinformatics 24, 2098-2100.

White, TJ., Bruns, T. Lee, S., Taylor, J. 1990. Amplification and direct sequencing of fungal ribosomal RNA genes for phylogenetics. In: Innis, M.A., Gelfand, D.H., Sninsky, J.J., White, J.W. (Eds.), PCR Protocols: A Guide to Methods and Applications. Academic Press, New York, pp. 315-322.

Winter, M. et al., 2009. Plant extinctions and introductions lead to phylogenetic and taxonomic homogenization of the European flora. Proc. Natl. Acad. Sci. U.S.A. $106,21721-21725$.

Winter, M., Devictor, V., Schweiger, O.,2013. Phylogenetic diversity and nature conservation: where are we? Trends Ecol. Evol. 28, 199-204. 